\title{
Análisis crítico sobre las nociones de poder y psicopolítica en el pensamiento de Byung-Chul Han
}

\author{
Autor: Alejandro Recio Sastre \\ Universidad Nacional de Educación, UNAE \\ alejandro.recio@unae.edu.ec; alejandrorecio13@gmail.com \\ Cuenca, Ecuador \\ https://orcid.org/0000-0001-6825-6326
}

Resumen

Byung-Chul Han es un autor cuyos ensayos son recién llegados en el desafiante mundo del pensamiento filosófico. Su noción del poder deriva en consideraciones políticas que el pensador ha denominado psicopolítica, signo de las formas de dominación predominantes en nuestros tiempos. Se podría decir que la noción ontológica del poder en Han determina la reflexión sobre una política que definitivamente toma como su objeto de dominación a la psique humana, dejando atrás a la biopolítica. Partiendo del análisis de su noción del poder, será posible realizar la crítica de la psicopolítica.

Palabras clave: psicología; intermediación; vigilancia; sociedad contemporánea.

Fecha de Recepción: 04-03-2019
Fecha de Aceptación: 20-06-2019
Fecha de Publicación: 05-08-2019 


\title{
Critical analysis on the notions of power and psychopolitics in Byung- Chul Han's thinking
}

\begin{abstract}
Byung-Chul Han is an author whose essays are new-comer inside of the philosophical thought's challenging world. His notion of the power drifts in political considerations that the thinker has named psychopolitics, sign of the preponderant political forms in our time. It might tell it the ontology notion of the power in Han determines the reflection about a politic that takes definitely as its domination object to the human psyche, drawing away to the biopolitical. Starting from the analysis of his notion power, it will be possible to perform the critic of the psychopolitics.
\end{abstract}

Keywords: psychology; conciliation; monitoring; contemporary society.

Date Received: 04-03-2019
Date Acceptance: 20-06-2019
Date Publication: 05-08-2019 


\section{Introducción}

Entre los manuales de filosofía y pensamiento político que se escribirán dentro de cincuenta años, probablemente el nombre de Byung-Chul Han aparezca como uno de los referentes más lúcidos de la reflexión filosófica de inicios de nuestro siglo. El autor surcoreano, radicado en Alemania, ha logrado sorprender a la comunidad académica mundial y se ha ganado un merecido puesto en las bibliotecas de intelectuales, académicos, expertos en estudios filosófico-políticos, sociales y antropológicos, y estudiosos en general.

Byung-chul Han logra concentrar temas de complejo calado en ensayos normalmente cortos y de no más de doscientas páginas. Utiliza un lenguaje simple, que no raya la mera simplificación banal, sino que aspira a explicar cuestiones profundas desde un discurso pulido y sin excesivas complicaciones terminológicas. El lenguaje filosófico que articula el ilustre pensador divide los argumentos en sentencias breves, pero de amplio contenido conceptual. Su estilo no consiste meramente en amalgamar oraciones sugerentes, más bien, modula sus reflexiones a partir de pensamientos que se transmiten de forma directa, sin incurrir en divagaciones superfluas enredadas entre párrafos con giros expresivos de difícil comprensión.

No cabe duda de que una de las virtudes más destacables de la obra de Han es su estilo. No conviene confundir este estilo con supuestas frases de dudosa inspiración -pero de aparente ingenio- que en algunas ocasiones encontramos en las redes sociales. Las sentencias de Han no culminan en meros Hashtags. Tampoco es una escritura que aspire a explicar filosofía de forma pedagógica, es decir, que pretenda hacer entendibles complejos pensamientos a principiantes. Han no es un escritor de manuales. Sus agudas críticas a los grandes filósofos vienen precedidas de explicaciones breves y condensadas sobre las ideas y sistemas de pensamiento de estos. Sin embargo, implanta una personalidad dentro de dichas explicaciones, en las que se denota una comprensión e interpretación originales. 
La filosofía de Han recurre a un estilo aforístico; transmite ideas mediante corrientes de palabras preñadas de rico pensamiento filosófico, con un contundente espíritu crítico y, también, mostrando un resignado malestar ante las sociedades actuales. Han sabe inculcar su desconfianza y marcado rechazo a muchos de los grandes conceptos que se reproducen repetitivamente hoy en día. Enemigo de la positividad, tan embaucadora y reinante en las relaciones digitalizadas actuales, nunca emite aserciones que pudieran evocar algún tipo de rencor o frustración fatalista. El cometido del autor, la función del pensador y la destreza del crítico se conjugan en una analítica de la civilización que trata de diagnosticar problemas, abusos, concepciones confusas y creencias pedestres dentro de todos los niveles de nuestra sociedad. Tanto en el ámbito intelectual como en los entornos más populares tienen lugar estas falencias civilizatorias. Han trata de diseccionar todas ellas.

No obstante, amén al propósito de este escrito, conviene desentrañar algunas de las debilidades y carencias en los planteamientos de Han. Unas debilidades cuyo talón de Aquiles se halla en una concepción del poder que, volcada hacia la psicopolítica, ha pretendido lapidar con demasiada presura a la biopolítica. Pese a lo admirable que pueda resultar la obra de Han, tanto en su estilo literario, como en su perspicaz analítica, así como también en lo que respecta a su astuta visión crítico-social, nuestras apreciaciones críticas a su filosofía no balbucean mientras se cuestiona el supuesto dominio psicopolítico al que el autor se restringe para explicar la política y la sociedad de nuestros días, amprándose en una determinada concepción del poder.

\section{El concepto de poder en Han}

El asunto del poder ha sido abordado desde la filosofía, la política, la ética y las ciencias sociales y humanas en general. A partir de la segunda mitad del siglo XX, tomó especial relevancia debido, a las muchas 
controversias y líneas de estudio abiertas por Foucault. Cuando Han da inicio a su reflexión en Sobre el poder, mediante un brevísimo prólogo, destaca el caos teórico que existe en torno a este concepto: resulta que algunos han visto en el poder opresión, lucha y violencia, mientras que otros han visto en él libertad, acción común y una radical separación con la violencia. De esta forma, el propósito del Han (2016a), consiste en:

hallar un concepto dinámico de poder capaz de unificar en sí mismo las nociones divergentes respecto a él. Lo que hay que formular es, por lo tanto, una forma fundamental de poder que, mediante la reubicación de elementos estructurales internos, genere diversas formas de manifestarse (págs. 9-10).

La reubicación que formula Han propone seccionar el poder en elementos estructurales desde los que comprender la composición inherente del poder y su inmanencia. Pero todo este ordenamiento comprensivo y, más que nada, interpretativo, responde a la noción de poder que el autor pretende justificar. Pero Han (2016b), compromete su concepción del poder a la posibilidad de su ejercicio excelente, pues supone que existe una forma absoluta y plena de poder: "Quien quiera obtener un poder absoluto no tendrá que hacer uso de la violencia, sino de la libertad del otro" (pág. 17). El poder en su forma perfecta haría coincidir la libertad y el sometimiento, a saber, articulando un sometimiento voluntario.

Sin embargo, dentro del primer elemento estructural interno donde se ubica el poder, correspondiente a la lógica, el Han (2016c), sostiene que: "el poder como coerción y el poder como libertad no son distintos. Solo se diferencian en cuanto al grado de intermediación" (pág. 37). Añade, además, que ambas manifestaciones tienen como punto de anclaje un mismo poder, pero que es el nivel de intermediación el que gradúa la continuidad de un determinado poder. De este modo la coerción coincide con un poder pobre en intermediación, mientras que, a mayor grado de intermediación, mayor 
estabilidad del poder, en la medida en que este se identifica más con la libertad. La perfectibilidad del poder tiene que ver, entonces, con el aumento e intensidad de sus intermediaciones, sin que se anule con ello la faceta agresiva que forma parte de él. A Han (2014a): lo estable e intermediado estarían vinculados a la racionalidad, que "corre paralela a la duración, la constancia y la regularidad" (pág. 72); al autor, solo le interesa evaluar el poder desde baremos meramente formales -así lo demuestra a lo largo de su análisis-, considera la perfectibilidad del poder en función de su forma gradual más estable. De este modo, se delata una comprensión del poder que reúsa hacer el estudio de su historia, que evade introducir una hermenéutica de su facticidad y que solo se remite a valorar su formalización en virtud de presumir que hay un grado supremo de poder.

Si la lógica del poder habilita las intermediaciones este también se infiltra en las comunicaciones. Con base en esto, el segundo elemento estructural del poder radicaría en la semántica. En él, el poder pasa de una dimensión formal a una simbólica: si lo simbólico del lenguaje es el symballein, la unión, para Han (2018a): a su lado siempre está el diaballein, la separación; el diaballein es el lado "diabólico" del lenguaje (pág. 160). En Sobre el poder no acepta que el cuerpo sea, tal como advirtió Foucault (2014): una "superficie de inscripción de los acontecimientos" (pág. 32). Precisamente, Han (2016d): le reprocha a Foucault una "amplia fijación con el cuerpo" (pág. 68) que no le permite ver el modo en que el poder actúa en el campo simbólico, creando hábitos. Antes que los acontecimientos, en el cuerpo se inscribe el lenguaje. El problema es que el poder nunca llega a verse enfrentado consigo mismo porque positiviza completamente al lenguaje, impidiendo que este se torne diabellein.

Una interpretación sociológica de la analítica heideggeriana de la cotidianidad descubriría que el "uno", aquel que domina las interpretaciones del mundo, es ese poder impersonal que a nadie pertenece; y que fluye entre 
los símbolos que precipita el lenguaje. El poder no se inscribiría sobre los cuerpos, sino que toma la figura de lo habitual. La consigna de Han (2016e), es clara:

El poder alcanza una estabilidad elevada cuando se presenta como <<uno>> impersonal, cuando se inscribe en la $<<$ cotidianidad $>>$. No es la coerción, sino el automatismo de la costumbre lo que eleva su eficiencia. Un poder absoluto sería uno que nunca se manifestara, que nunca se señalara a sí mismo, sino que, más bien, se fundiera del todo en la obviedad. El poder brilla por su ausencia (pág. 78).

El tercer elemento estructural del poder en el ordenamiento de Han es la metafísica. Aquí el autor irrumpe en su propio discurso, pues retoma aquella ontología del poder aplazada. De forma camuflada el pensador coreano ya había dado una pauta ontológica sobre el poder: su realidad se produce en medio de las relaciones humanas, mas, por ello, se refuerza a través de la riqueza de intermediaciones que le otorgan continuidad. El poder es intermediación continuada, pero no un juego. Cuando "el otro" admite libremente actuar según la voluntad de un "yo", el poder se continúa a sí mismo en el orden de la voluntad y no de la mera coacción. La pobreza del poder se expresa cuando "el otro" actúa contra su voluntad, forzado por la decisión unilateral de un yo que le impele movimiento como si de una cosa pasiva se tratara.

El autor pone especial interés en interpretar algunas nociones de Hegel en vinculación con su propia concepción del poder. Ve en el pensamiento del célebre filósofo alemán una identificación clara entre el poder y la libertad; todo comienza con la subjetividad, que, mientras busca encerrarse en sí misma, crea un espacio ipso-céntrico del poder, es decir, un espacio diferenciado de toda exterioridad. Pero como el poder en su máxima pureza ha de ser distinto de la violencia, esta última carece de concepto, ya que el concepto se encuentra en confrontación con la realidad, aunque sin ponerla bajo coacción. 
La realidad se hace transparente con respecto al concepto que la alumbra. Entonces, la verdad es poder. De modo que Han (2016f): encuentra que el concepto de poder puede entenderse desde "lo universal, es un $<<$ poder libre>> en la medida en que no se limita a <<someter >> lo distinto (...) bajo sí, sino que lo deja salir o lo libera bajo su esencia" (pág. 101).

Según Ruiz del Ferrier (2018a): Han distingue dos elementos en el poder: el espacio y las comunicaciones. El poder genera su propio espacio, él mismo se funde en ese espacio, igualmente, una vez queda habilitada su espacialidad, el poder orienta las comunicaciones sin recurrir a la coacción. El poder construye y produce la comunicación dentro de su propio espacio (págs. 35-36). A ojos de Ruiz del Ferrier (2018b): lo que sucede en el pensamiento de Han es que la ontología de la política entendida como conflicto queda desactivada. El sujeto haniano está replegado en su ser-intimo, renuncia al espacio intersubjetivo de la política para recluirse en la subjetividad (pág. 43). De este modo, las obras de Han invitarían a la inacción y a la contemplación individualizada, no pretende recuperar ese contrapoder que reactivaría ontológicamente lo político.

Para Ruiz del Ferrier (2018c): "las prácticas de constitución de las identidades políticas construirán nuevas formas de resistencia, de transformación, de libertad, de poder y de emancipación" (pág. 56); -esto se corresponde más bien con un deseo de la autora-. Pero la cuestión en este punto es mucho más aguda, pues no se trata únicamente de ocupar de nuevo el espacio político perdido por el demos, de hecho, si algo hay que reconocerle a Han, es que es completamente consecuente con su propio análisis del poder cuando elabora su crítica social. Lo que ocurre es que el pensamiento del autor queda atrapado en su propia ontología monista del poder. Quizá muchos individuos y colectividades se hallen en esta situación hoy en día, por lo que los postulados de Han no son nada especiales al respecto. La metafísica del poder de Han parte de un monismo que apresa toda diferencia, recluyendo 
también a la libertad, la cual se demuestra idéntica al poder. El monismo ontológico del poder es un monismo subjetivo porque ni siquiera expone las diferencias entre lo corpóreo y la subjetividad.

El cuarto elemento estructural del poder es la política, que coherentemente aparece una vez se ha tomado una posición ontológica sobre el poder -o metafísica, si se prefiere-. Y el quinto es la ética. Han interpone la política a la ética; pero no justifica por qué lo hace. El autor considera prioritario dar a conocer la "Política del poder" para después ceñirse a la cuestión de la "'Ética del poder". Pero lo que verdaderamente le preocupa es justificar el vínculo estrecho y casi inefable entre el poder y la libertad, un asunto que culmina en la Ética y que se posterga en pro de asumir un absurdo como es la "Política del poder". Esto es un absurdo porque desdobla el concepto de poder, ya que supone que lo político puede ser un concepto regulador de su propia coyuntura. Toda política en sí es actividad, gestión, intensificación, reducción, correlación, lucha, desafección, desintegración o concentración del poder, y, en consecuencia, el objeto de la política se origina en las mismas relaciones de poder. Por tanto, una "política del poder" no sería más que el poder del poder.

Y luego de este desdoblamiento petulante e insólito Han culmina con la Ética del poder, donde prepara un giro final que generará aún mayor perplejidad:

Resulta que Han (2016g): encuentra una ética del poder frustrada en el pensamiento de Nietzsche. La encuentra en la "sobreexcedencia" del poder de la nobleza, que termina volviéndose hospitalidad por su carácter amable. Precisamente la sobreexcedencia hace lindar al poder con su distinto. De modo que el poder se deja perder a sí mismo antes de toda preocupación por el otro, su nobleza, su autoindulgencia, distinta del poder violento de la dominación, deja la filosofía nietzscheana de la voluntad de poder 
deambulando en la impersonalidad del no-deseo, como una ética y una estética del nadie (págs. 175-178). Cabe mencionar que para Han la voluntad de poder se ve frustrada justo cuando el poder abunda tanto como para rebasar el prioritario quererse-a-sí-mismo. El poder está condenado a lidiar con lo distinto de sí mismo en el momento en que se ennoblece, cuando sobreabunda y se sobreexcede.

Sin embargo, Han no tiene en cuenta los dos niveles del poder desde los que habla Nietzsche: uno es el de la voluntad de poder y el otro es el del poder como concepto creado por los seres humanos. Buena muestra de ello es el aforismo titulado Sobre el "maquiavelismo" del poder, en el que Nietzsche (2008), afirma que: "el poder en la 'voluntad de poder' es solo un medio: el protoplasma que se apropia de algo y lo integra al organismo, que por lo tanto se fortalece y ejerce poder para fortalecerse" (pág. 280). El poder que no es voluntad de poder y, a saber, es "poder político", para Nietzsche no es más que un medio al servicio de la voluntad de poder.

Las formas de poder político, es decir, el status público que adquieren ciertos individuos, las instituciones, la legitimidad, o el ejercicio de mando por parte de unos sobre otros, son el resultado de las relaciones que los seres humanos entablan en la vida social, tras las que late la voluntad de poder. El poder es una forma mediata de la voluntad de poder, su instrumento, pues esta es principio y fin de la vida social en particular y de toda forma de vida en general. El dominio que opera en el nivel de las instituciones, del gobierno, de los códigos éticos, de los protocolos, etc., no es más que un producto inconsciente de la voluntad de poder, que es la causa de las correlaciones sociales y la que está tras las composiciones instituyentes erigidas. El poder instrumental creado en la sociedad, que no es otra cosa que un poder político, es solo un medio y nunca un fin. En cierto sentido, podría afirmase que quien inclina su vida a tomar ese poder como su objeto último, desconoce la voluntad de poder. 
De acuerdo a lo establecido, se demuestra la inconveniencia de mentar a Nietzsche en un texto que lleva bajo título "Ética del poder". El poder no puede tener tras de sí una ética sino tan solo una voluntad, una voluntad de poder, puesto que en el trasfondo de la ética está la voluntad de dominar. Y bajo estas mismas premisas -huelga recordar- se advierte también la imposibilidad de plantear una política del poder, pues no hay modo de concebir al poder como objeto de saber y administración de sí mismo. Para ello habría que crear una instancia superior al poder que por excelencia opera en la política, tal y como hace Nietzsche, quien considera a la voluntad como verdadera depositaria del poder y no solo como su mera representación en el campo de las relaciones sociales.

Así, entonces, el análisis estructural del poder planteado por Han llega a un absurdo en su etapa final: no es coherente afrontar el tema del poder subordinando su noción a disciplinas nacidas por mor del poder. Tras los asuntos éticos y políticos opera como telón de fondo el entramado del poder. El poder adquiere espesor y forma en las relaciones morales y políticas. Han podría haberse mostrado presto a considerar una genealogía del poder, una fenomenología, o, por qué no, una hermenéutica, dado que lícitamente cabe tomar al poder(político) como un producto de la historia, de la conciencia o de los cálculos inherentes a la dominación y a la resistencia.

\section{Psicopolítica: ¿superación de la biopolítica?}

Una de las tesis más controvertidas de Han afirma la obsolescencia de la biopolítica en el contexto social actual. Sostiene que Foucault no tuvo éxito en su intento de localizar qué es la biopolítica. Una vez Foucault se dio cuenta de que el análisis de los regímenes disciplinarios no reflejaba fielmente la época en que él vivía, se volcó a estudiar las formas de gobierno en el contexto neoliberal, pero siempre a la luz de los términos "población" y "biopolítica". Para Han (2014b): Foucault vio que población y biopolítica solo encajan 
conceptualmente en las sociedades disciplinarias, ya que son incapaces de describir fielmente a las sociedades neoliberales (págs. 39-40). Si Foucault asoció la biopolítica con una disciplina capitalista, entonces, el destino de la biopolítica quedó unido al de los cuerpos, siendo así que, sin embargo, la gubernamentalidad neoliberal trató de ir más allá. Afirma Han (2014c):

El neoliberalismo como una nueva forma de evolución, incluso como una forma de mutación del capitalismo, no se ocupa primeramente de lo <<biológico, somático, corporal >>. Por el contrario, descubre la psique como fuerza productiva. Este giro a la psique, y con ello a la psicopolítica, está relacionado con la forma de producción del capitalismo actual, puesto que este último está determinado por formas de producción inmateriales e incorpóreas. No se producen objetos físicos, sino objetos nofísicos como informaciones y programas (págs. 41-42).

El giro a la psique protagonizado por el capitalismo actual relegaría la corporalidad a una insignificante irrelevancia. La producción del valor parte de la dimensión psíquica humana. Con ello, el pensador coreano justifica su visión del poder como algo incorporal, ya que, si este se identifica con la libertad, necesariamente será incorpóreo, pues el concepto de libertad no es análogo a los procesos físicos. La libertad no es identificable con ningún objeto físico, por tanto, el poder tampoco lo sería. Han (2014d): sostiene que la eficiencia del poder-libertad consiste en que no domina al individuo contra su voluntad pues de lo contrario habría que incurrir en extensos costes al desplegar medios físicos para la coacción-, sino que se apodera indirectamente de la voluntad del individuo a través de su psique (pág. 46).

En Psicopolítica Han separa lo corporal del poder. La empresa que lleva a cabo el autor restringe la noción de poder a la inmaterialidad de lo que podría denominarse la vida psíquica de los seres humanos. Esta vida psíquica es una dimensión que Han escinde de todo lo relativo a la corporalidad. De modo que su consideración de "psicopoder" no se origina en la inmanencia corporal sino en la inmanencia de la psique, como si esta fuera algo diferente del cuerpo, 
como si no hubiera una síntesis originaria en la que psique y cuerpo aparecen unidos e indistintos el uno del otro. Al ceñirse a la inmanencia psíquica, Han no está hablando de un poder originario a la vida en su totalidad, ni mucho menos de un "poder puro" -suponiendo que lo hubiera-. Han está disponiendo de la clásica división, tanto antigua como moderna, que separa la corporalidad de un otro inmaterial, ese otro inmaterial que bien podría ser considerado alma, espíritu, mente, psique, etc. Entonces, al partir de esta no-participación del cuerpo en el desarrollo del poder, la ontología psicopolítica incide en la misma fisura mediante la que buena parte de la historia de la filosofía constituyó al poder-dominación. Todo poder-dominación es extrínseco a la inmanencia vital del cuerpo. La inmanencia haniana reside en un elemento ya tomado como escindido del cuerpo: la psique.

La dominación de la que habla Han toma la forma de un poder que coincide con la libertad, o al menos con aquello que hoy en día se dice que es la libertad. Si la libertad es voluntad libre, entonces, por voluntad propia el individuo puede someterse a un poder externo e indiferente a los intereses que subyacen a su vida en tanto que integración plena cuerpo-psique. Aunque psíquicamente el individuo esté convencido de lo que quiere o de lo que hace, este, puede auto-infligirse daño, incluso, es capaz de auto-coaccionarse. En este punto comienza a verse el conflicto que Han crea en su propia filosofía: resulta que el poder no es violencia, nada tiene que ver con ella, sin embargo, el poder en coincidencia con la libertad causa que el individuo pueda dañarse a sí mismo por voluntad propia.

De manera esquiva y quizá de casualidad, Han (2018b): expresa que no se trata de una violencia físico-coactiva ni ejercida directamente sobre los cuerpos, sino de una "violencia simbólica, sin necesidad de violencia física" (pág. 119); y termina reconociendo la presencia de un nódulo inquebrantable entre el poder y la violencia que mantiene la dominación; pero la violencia no física igualmente es violencia (pág. 120). ¿Cómo pueden entonces alcanzar 
un punto en común las estructuras diferenciadas del poder y la violencia? La respuesta es que esto sucedería allí donde la violencia se disuelve en el poder, es decir, cuando hay una mediación simbólica que hace pasar a la violencia como consentimiento voluntario. El problema al respecto es saber si Han en algún momento terminó de perder de vista la violencia en el poder, o si Topología de la violencia es la obra en la que, tibiamente, el autor recula y reconoce que su intento de pensar una forma pura del poder idéntica a la libertad era una mera argucia para encubrir la violencia que siempre está latente en la dominación. De ser lo segundo, reconocería Han que la psicopolítica se cimienta sobre un fraude que él mismo abaló y abanderó.

Otros dos términos que Han (2014e): hace coincidir en su caracterización de las sociedades contemporáneas son la comunicación y la vigilancia: menciona a "El Big Brother amable" (págs. 59-65), que supera con creces al sistema de vigilancia disciplinaria del panóptico de Bentham. En la actualidad no predomina un sistema disciplinario ni cabe emplear el término "Estado vigilante", inspirado en la novela de Gerorge Orwell en el año 1984. En ningún caso las cámaras se utilizan para reprimir o coaccionar, sino que cada uno se expone voluntariamente a la cámara que tiene en su Smartphone. Hay una nueva sociedad de control en la que, según Han (2014f): la comunicación y el control adquieren coincidencia plena, haciendo que cada individuo sea "el panóptico de sí mismo" (pág. 63).

Este sistema de control auto-admitido y aceptado por voluntad de los individuos es objeto de la asimilación acrítica de la transparencia como positividad. Para Han (2013a): Ia transparencia encierra a toda la sociedad, privándola de su "afuera", es intolerante a cualquier negatividad (pág. 22). La sociedad de la transparencia requiere vías de comunicación e información rápidas, con canales saturados de datos. Esta saturación crea espacios transparentes despolitizados porque en ellos ya no se puede hallar verdad alguna. La ausencia de verdad se hace notar allí donde lo positivo se masifica. 
Han (2013b), considera que la hiperinformación e hipercomunicación: "no inyectan ninguna luz en la oscuridad" (pág. 80).

Existe una fascinación por la transparencia en las sociedades de hoy que Han repudia. El triunfo absoluto de lo positivo ha arruinado toda dialéctica del sujeto, toda posibilidad de distinguir entre una verdad y una falsedad. Ambos términos se han diluido en la positivización de la sociedad. La fascinación por la transparencia viene causada por ese dominio absoluto de lo positivo. El exceso de positividad excluye cualquier distinción, así, la mismidad crea el infierno de lo igual. Han (2017): afirma que dentro del "infierno de lo igual ya no resulta posible ningún anhelo de lo distinto" (pág. 9). El espacio digital transparente incluye todo lo igual. La exposición de los individuos y sus sentimientos en las redes sociales y la datalización de la vida siguen adelante simplemente porque resultan rentables. Para Han (2014g), lo opaco e inaccesible no entra dentro de la concepción positiva y transparente de las cosas:

El imperativo de la segunda llustración es: se ha de convertir todo en datos e información. El dataísmo, que pretende superar toda ideología, es en sí mismo una ideología. Conduce al totalitarismo digital. Por eso es necesaria una tercera llustración que revele que la ilustración digital se convierte en esclavitud (pág. 88).

La racionalidad de la primera llustración reprimió a la imaginación, a la corporalidad y al deseo. Y la segunda llustración, mediante la información, los datos y la transparencia, acabará con los mitos volviéndose a sí misma una mitología. La acumulación y flujo de datos no alcanza a abarcar un sentido. La narrativa sí conforma un relato de sentido, mientras que el dataísmo tan solo genera un espacio henchido de datos, pero huero de sentido. Según Domínguez (2019): en los sistemas educativos no se han producido diseños que complementen suficientemente la formación en competencias digitales con las demandas de la Cibersociedad (pág. 325); por eso, la ilustración 
dataísta aún se articula como una "mitología" más que como una realidad practicable en el terreno educativo.

Tras comentar cómo opera la sobreabundancia dataísta Han se centra en el sí mismo como objeto de datificación. En este punto recupera el estudio de Foucault sobre las tecnologías del Yo. Concretamente Han se fija en cómo Foucault vio en la escritura una actividad para llevar a cabo el cuidado de sí. A ojos de Foucault (2008): el sí mismo es un tema literario, algo sobre lo que vale la pena escribir (pág. 62). Pero este modo de cuidar de sí en nuestro tiempo, según Han (2014h): habría perdido todo su componente ético debido a que el dataísmo renuncia a buscar la verdad (pág. 93). Nuestro Yo se ha convertido en nuestro vigilante en la medida en que nos hemos vuelto empresarios de nosotros mismos, en la medida en que nos autoexplotamos y en la medida en que somos simultáneamente víctima y verdugo.

La positividad social, el totalitarismo de la mismidad excluyente de lo distinto, la transparencia coercitiva y el "mito" dataísta conforman la columna vertebral desde la que Han analiza al ser humano del presente histórico. El individuo ya no puede recurrir a un relato de sí porque no se distingue de los otros. No hay sujeto que busque conocerse para alcanzar una verdad; el encuentro con el Yo es el encuentro con alguien que me vigila. El enjambre digital en el que está inmerso el sujeto produce una sociedad del rendimiento que aísla a los individuos, lo que conlleva el ejercicio de la violencia contra uno mismo en tanto en cuanto "el otro" desaparece. Han (2014i), dice que:

El sujeto de rendimiento se explota a sí mismo, hasta que se derrumba. $Y$ desarrolla una autoagresividad que no pocas veces desemboca en el suicidio. El sí mismo como bello proyecto se muestra como proyectil, que se dirige contra sí mismo (pág. 76).

La psicopolítica ha cambiado el paradigma del panoptismo como forma de ejercer un domino disciplinario sobre la sociedad. El psicopoder sustituye 
al biopoder. La vigilancia digital puede llegar a controlar los pensamientos, en este aspecto, la dominación de los cuerpos se vuelve innecesaria. Para Han (2014j): el problema de la biopolítica, radica en que "no permite ninguna intervención sutil en la dimensión psíquica de los hombres. En cambio, el psicopoder está en condiciones de intervenir en los procesos psicológicos" (pág. 106).

Pero, ¿por qué la gubernamentalidad de este psicopoder sigue necesitando armas de agresión física y sofisticados materiales bélicos contra los cuerpos para seguir manteniendo el orden global? ¿No se percata Han de que en el mundo de hoy aún existen muchas poblaciones que viven al margen de las redes digitales, sin medios para conectarse a Internet y a expensas del raudal informativo de las sociedades occidentales? Estas preguntas evidencian la parcialidad del sujeto que describe Han. No habla de un sujeto universal -ni es esta una de sus pretensiones- pero sí habla de un sujeto en abstracto -quizá porque siempre que se habla de un "sujeto" se recurre a abstracciones inevitables-. Podría decirse que el conjunto de sujetos que tienen acceso a las redes de información y comunicación crean un sistema de aislamiento con respecto a los que viven a expensas o privados de esta accesibilidad. El análisis de Han solo se centra en los que tienen acceso. Ellos, de manera voluntaria, se someten al psicopoder, cuyo alcance sigue siendo limitado.

El poder se combina con sistemas de dominación físicos y psíquicos, los físicos no están menos avanzados, perfeccionados y refinados tecnológicamente. La autoinclusión en el espacio digital es a la vez una autoexclusión con respecto a lo que está fuera de ese espacio. El psicopoder domina a los que están dentro del espacio digital, gobierna sobre estos en la medida en que voluntariamente aceptan ser transparentados, pues gustosamente se exponen al control. Articulan contra sí mismos mecanismos de agresión psicopolítica. Sin embargo, los que están afuera de esa positividad 
y transparencia siguen siendo controlados por un biopoder cada vez más desarrollado a nivel tecnológico y con mayor capacidad de destrucción. Eso no preocupa realmente a los sujetos aislados e incluidos en las redes digitales, que ven el mundo como un circuito de información y valoran las cosas como un conjunto de datos, sin preocuparse por dar alcance a ninguna verdad, y únicamente pendientes de la transparentación de todo y de ellos mismos. Aun así, la capacidad destructiva del biopoder, que sigue recurriendo a la coacción y a la violencia física, es evidente, pero la atención y sentimientos que provoca son efímeros en el mundo hiperdinamizado de las comunicaciones digitales.

Han hace filosofía de los autoincluidos y aislados en el espacio digital. En cierto modo, Han piensa la política desde este aislamiento. Su crítica social no aspira a salir del espacio de auto-in reclusión en el que se encierra al sujeto sobre el que reflexiona. A pesar de que Han (2012): no admite la faceta inmunitaria en las sociedades contemporáneas (págs. 8-10); sí inmuniza su propia filosofía cuando anuncia una negatividad excluida pero siempre ontológicamente presente, precisamente no quiere ver en la neutralización de las diferencias (pág. 14); el triunfo de la política inmunológica, igualmente reúsa indagar en el contenido de poder inmanente a la corporalidad humana, un poderío que su psicopolítica encubre. De esta forma, Esposito (2009), diría al respecto, que lo negativo: "no es eliminable, sino solo domesticable (...)" (pág. 141).

\section{Conclusiones}

Las nociones de poder y psicopolítica de Byung-Chul Han se afirman sobre la base de una ontología política que niega el poderío que albergan los cuerpos humanos. La base ontológica de su concepto de poder no tiene raigambre en el conjunto de fuerzas que interaccionan en el espacio físico de la política, fuerzas que vienen originalmente integradas a las redes psicológicas y subjetivas que contribuyen al movimiento, dirección o parálisis 
de cuerpos individuales y multitudinarios. Han psicologiza y subjetiviza el poder, conceptualiza un psicopoder del que surge la psicopolítica. Articula sus argumentos y consideraciones habiendo tomado por válida la autonomía y libertad de la dimensión subjetiva humana, como si esta, de hecho, estuviera escindida de la corporalidad.

El resultado de tales preconcepciones a la hora de caracterizar una noción de poder y de presentar una consecuente concepción de lo político implica una filosofía que explora con mucha pertinencia y agudeza los elementos psicológicos y filtros heterónomos de la construcción de la subjetividad. Nadie le niega a Han sus grandes aciertos en lo que se refiere a esta indagación sobre la dimensión invisible humana, aquella que reside, si es que reside en alguna parte, en el interior de los cuerpos y que no se deja transparentar más que por la voluntad de los sujetos. La propia voluntad de los otros es invisible para nosotros, la subjetividad es intransparentable, a menos que los mecanismos de manipulación de la voluntad produzcan un sujeto que desee visibilizar todos los aspectos de su vida pese a volverse con ello más manejable.

Quizás a Han le falta percatarse de los efectos políticos, no patológicos, que causa en la corporalidad el poder-dominación asimilado a la voluntad, pues cuando psique y dominación se mimetizan, la causalidad que existe entre la fabricación invisible de un sujeto y el uso de las fuerzas subyacentes a los cuerpos sustrae por completo la capacidad que tiene el cuerpo social para erigirse como poder.

\section{Referencias}

Domínguez, M. (2019). La Cibersociedad: Modelo por Competencias Digitales y Desafío en la formación Profesional del Profesor Universitario. Revista Scientific, 4(12), 312-328, e-ISSN: 2542-2987.

Recuperado de: 


\section{https://doi.org/10.29394/Scientific.issn.2542-2987.2019.4.12.16.312-}

$\underline{328}$

Esposito, R. (2009). Immunitas: Protección y negación de la vida.

Colección: Mutaciones, ISBN: 9505187173; ISBN: 978-950-518-717-1.

Buenos Aires, Argentina: Amorrortu.

Foucault, M. (2014). Nietzsche, la Genealogía, la Historia. ISBN: 978-8485081-97-4. Valencia, España: Editorial Pre-Textos, 76 págs.

Foucault, M. (2008). Tecnologías del Yo. 1ra. Edición, ISBN: 978-950-125026-8. Buenos Aires, Argentina: Editorial Paidós, 152 págs.

Han, B. (2018a,b). Topología de la violencia. ISBN: 978-84-254-3418-1. Barcelona, España: Herder Editorial, S.L.

Han, B. (2017). La expulsión de lo distinto. 1ra. Edición Digital, ISBN: 97884-254-3966-7. Barcelona, España: Herder Editorial, S.L.

Han, B. (2016a,b,c,d,e,f,g). Sobre el poder. 1ra. Edición digital, ISBN: 978-84254-3856-1. Barcelona, España: Herder Editorial, S.L.

Han, B. (2014a,b,c,d,e,f,g,h). Psicopolítica. Colección: Pensamiento Herder, ISBN: 978-84-254-3398-6. Barcelona, España: Herder Editorial, S.L.

Han, B. (2014i,j). En el enjambre. 1ra. Edición digital, ISBN: 978-84-254-3368-

9. Barcelona, España: Herder Editorial, S.L.

Han, B. (2013a,b). La sociedad de la transparencia. ISBN: 978-84-254-3252-

1. Barcelona, España: Herder Editorial, S.L.

Han, B. (2012). La sociedad del cansancio. ISBN: 978-84-254-2910-1. Barcelona, España: Herder Editorial, S.L.

Nietzsche, F. (2008). Fragmentos póstumos (1885-1889). Volumen IV, 2da. Edición, ISBN: 9788430946785. Madrid, España: TECNOS.

Ruiz del Ferrier, M. (2018a,b,c). Poderes. En Espinosa, L., Greco, M.B., Penchaszadeh, A.P., Ruiz del Ferrier, M.C. y Sferco, S. (Ed.), ¿Por qué [no] leer a Byung-chul Han? ISBN: 978-987-45921-5-6. Buenos Aires, Argentina: Ubu Ediciones, págs. 29-57. 


\section{Alejandro Recio Sastre \\ e-mail: alejandro.recio@unae.edu.ec; alejandrorecio13@gmail.com}

Nacido en Salamanca, España, el 7 de abril del año

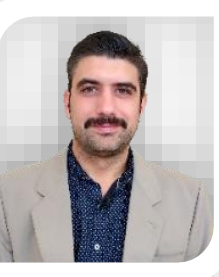
1990. Licenciado en Filosofía por la Universidad de Salamanca (USAL, 2013); y magister por la misma universidad (2014); Doctor en Filosofía Política por la Universidad de Valladolid (Uva, 2018) y la Universidad de Chile (Uchile, 2018); Título de mi tesis: Cuerpo y poder desde los albores de la modernidad. El lugar del poder en relación con la corporalidad en el sujeto, la sociedad y sus articulaciones. Actualmente soy docente-investigador en la Universidad Nacional de Educación (UNAE) del Ecuador.

El contenido de este manuscrito se difunde bajo una Licencia de Creative Commons ReconocimientoNoComercial-Compartirlgual 4.0 Internacional 